\title{
How does the complex structure and size of Boom Clay natural dissolved organic matter affect its reactivity towards radionuclides?
}

Buchatskaya Yu. ${ }^{1,2}$, Salah S. ${ }^{2}$, Durce D. ${ }^{2}$, Devillers M. ${ }^{1}$, Steudtner R. ${ }^{3}$

${ }^{1}$ Université catholique de Louvain, Louvain-la-Neuve, Belgium, ybuchats@sckcen.be

${ }^{2} \mathrm{SCK} \cdot \mathrm{CEN}$, Mol, Belgium

${ }^{3}$ Helmholtz-Zentrum Dresden-Rossendorf, Dresden, Germany

doi: 10.36291/HIT.2019.buchatskaya.023

In the context of radioactive waste disposal, Boom Clay (BC) is considered as one of the potential host rock formations for the storage of high-level and long-lived (HLW-LL) radioactive waste in Belgium. Boom Clay was deposited in seawater approximately 30 million years ago and is mainly composed of siliciclastic minerals, carbonates and organic matter. Significant part of the BC organic matter (up to $250 \mathrm{mg} \mathrm{C/L}$ ) occurs in dissolved form, meaning it passes - by definition - a $0.45 \mu \mathrm{m}$ filter. This dissolved organic matter (DOM) differs in size (from hundreds to thousands of Da, Fig. 1), solubility at different $\mathrm{pH}$ values (humic and fulvic acids), structure (aliphatic versus aromatic) and reactivity (functional groups). Previous studies [1] showed that DOM can form complexes with uranium and thus, influence the geochemical behavior of uranium, however the complex structure of natural DOM was not taken into account so far.

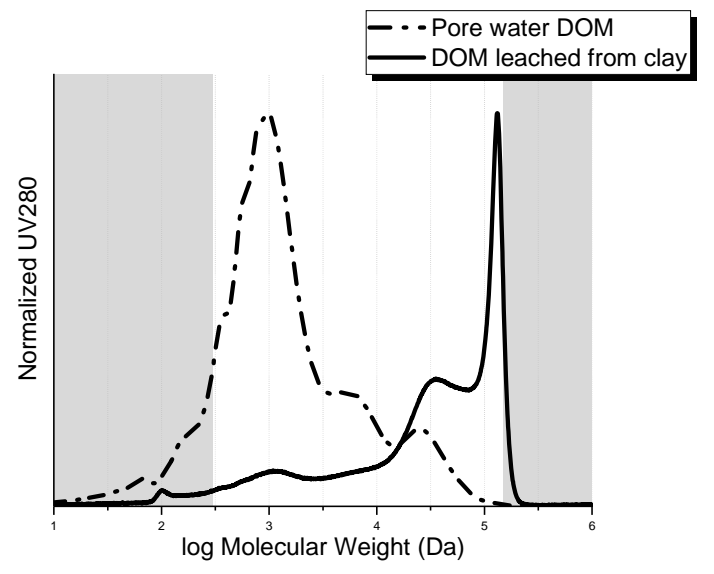

Figure. 1. Mw distributions of BC DOM obtained by size-exclusion chromatography (SEC) coupled to UV-Vis 280 for DOM obtained by piezometer sampling (pore water DOM) and for DOM leached from BC sample from HADES underground laboratory in Mol, Belgium.

Therefore, two fractions of natural DOM were chosen to investigate their binding properties towards uranium: a "small" $(<1 \mathrm{kDa})$ and a "colloidal" $(0.45 \mu \mathrm{m}-100 \mathrm{kDa})$ fraction. The small fraction was separated using ultrafiltration with 1 kDa PES membranes from BC pore water sampled under in-situ conditions in the underground HADES facility $(\sim-223 \mathrm{~m})$. The colloidal fraction (Ex-045-100) was separated by leaching DOM with UP water from a Boom Clay core, filtering it and recuperating the residue from $100 \mathrm{kDa}$ PES membranes. The current study is focused on the isolation, purification, and characterization of the colloidal DOM fraction using UV-Vis, SEC, X-ray Photoelectron Spectroscopy, chemical and elemental analysis and potentiometric titrations. Besides this, the binding properties of the colloidal fraction towards uranium were evaluated through determination of conditional complexation constants using TRLFS and UC experiments.

References

1. Dierckx A. et al. Transport of radionuclides due to complexation with organic matter in clay formations(Trancom-Clay). EUR(Luxembourg) 2000. 